\title{
Remodelación ósea tras el tratamiento quirúrgico del quiste óseo aneurismático de localización metacarpiana en el niño
}

\author{
F. Soldado-Carrera ${ }^{(1)}$, J.P. García de la Fuente ${ }^{(1)}$, A. Arcalís ArCe ${ }^{(1)}$, \\ M. Aguirre i CANYAdell ${ }^{(2)}$ \\ (I)Servicio de Cirugía Ortopédica y Traumatología. Hospital Universitario Vall d' Hebron. \\ BARCELONA.

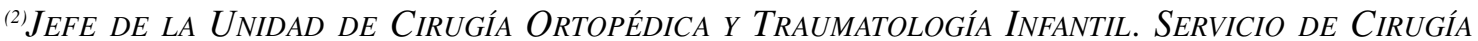 \\ Ortopédica y TRaumatología. Hospital Universitario Vall d’ Hebron. Barcelona.
}

\section{Correspondencia:}

Francisco Soldado Carrera

Unidad Ortopedia Infantil

Hospital Materno-Infantil. Hospital Universitario Vall d'Hebron

Paseo de la Vall d'Hebron, 119-139

08035 Barcelona España

Teléf. 934893325

E-mail: 34194fsc@comb.es

El quiste óseo aneurismático localizado en la mano es poco frecuente.

No se ha descrito su incidencia real en la infancia, ni la influencia que sobre la evolución del tumor puede tener la presencia de cartílagos de crecimiento abiertos.

La remodelación ósea permite que el hueso cambie de forma ("reshaping") o sea sustituido después de una lesión.

Presentamos el caso de un QOA localizado en el cuarto metacarpiano de la mano derecha en una niña de 5 años de edad. Fue intervenida y a los nueve años de seguimiento se objetivó una remodelación tubular completa del metacarpiano. La eliminación del factor lesivo y la presencia de cartílagos de crecimiento abiertos ha permitido la retubulización.

Palabras clave: Quiste óseo aneurismático, tumor mano, tubulización ósea.
The Aneurysmatic Bone Cyst located in the hand is unusual. There is not information about its real childhood incidence nor influence about the presence of active growth cartilage in the tumour evolution.

Osseous redesigning allows that the bone changing shape (reshaping) or even could be replaced after injure.

We are presenting the case of an $\mathrm{ABC}$ located in the fourth metacarpal on the right hand in a young girl, five years old. She was surgical intervened and monitored when she was nine years old. It was found a total tubular metacarpal reshaping. The elimination of the injurious factor and the presence of active growth cartilages have allowed the tubular regeneration.

Key words: Aneurysmatic bone cyst, hand tumor, bone tubulation. 
$\mathrm{E}$ 1 quiste óseo aneurismático (QOA) representa aproximadamente el 5\% de los tumores óseos benignos. Su localización en la mano es poco frecuente, pues únicamente el 3-5\% de los QOA se presentan a dicho nivel (Borrelli et al., 1994). El 62\% de los QOA que se localizan en la mano afectan a la region metacarpiana (Frassica et al., 1998).

Hasta el momento no se ha descrito su incidencia real en la infancia, ni tampoco la influencia que sobre la evolución del tumor puede tener la presencia de cartílagos de crecimiento abiertos y fértiles (Burkhalter et al., 1978).

Como es conocido, la remodelación ósea permite que el hueso cambie de forma ("reshaping") o sea sustituido durante el crecimiento o después de una lesión.

Presentamos el caso de un QOA localizado en el cuarto metacarpiano de la mano derecha en una niña de 5 años de edad. Fue intervenida y a los nueve años de seguimiento se objetivó una remodelación tubular completa del metacarpiano.

\section{CASO CLÍNICO}

Niña de 5 años de edad que acudió a consultas externas refiriendo la aparición de una tumoración no dolorosa, de crecimiento lento y sin antecedente traumático en la zona cubital del dorso de la mano derecha.

A la exploración presentaba una masa de aproximadamente $4 \times 2 \mathrm{~cm}$ de localización dorsal en la región del cuarto metacarpiano de la mano derecha (Figura 1). No asociaba ningún

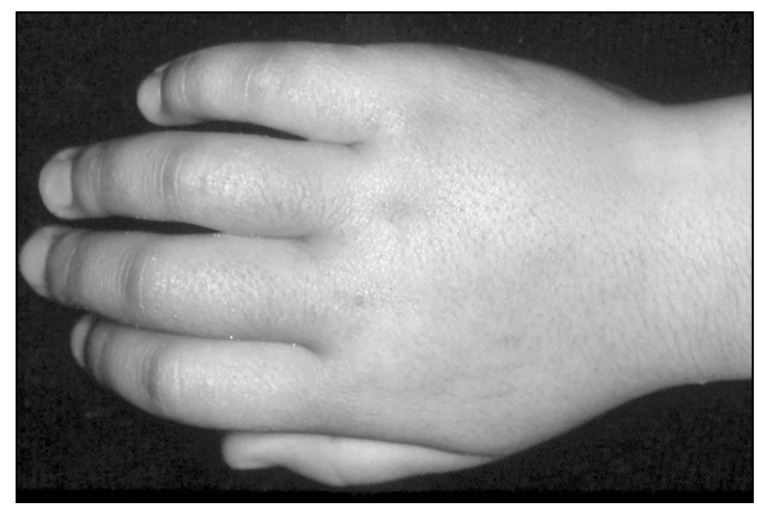

Figura 1. Aspecto clínico: Tumoración en región del $4^{o}$ radio del dorso de la región metacarpiana.

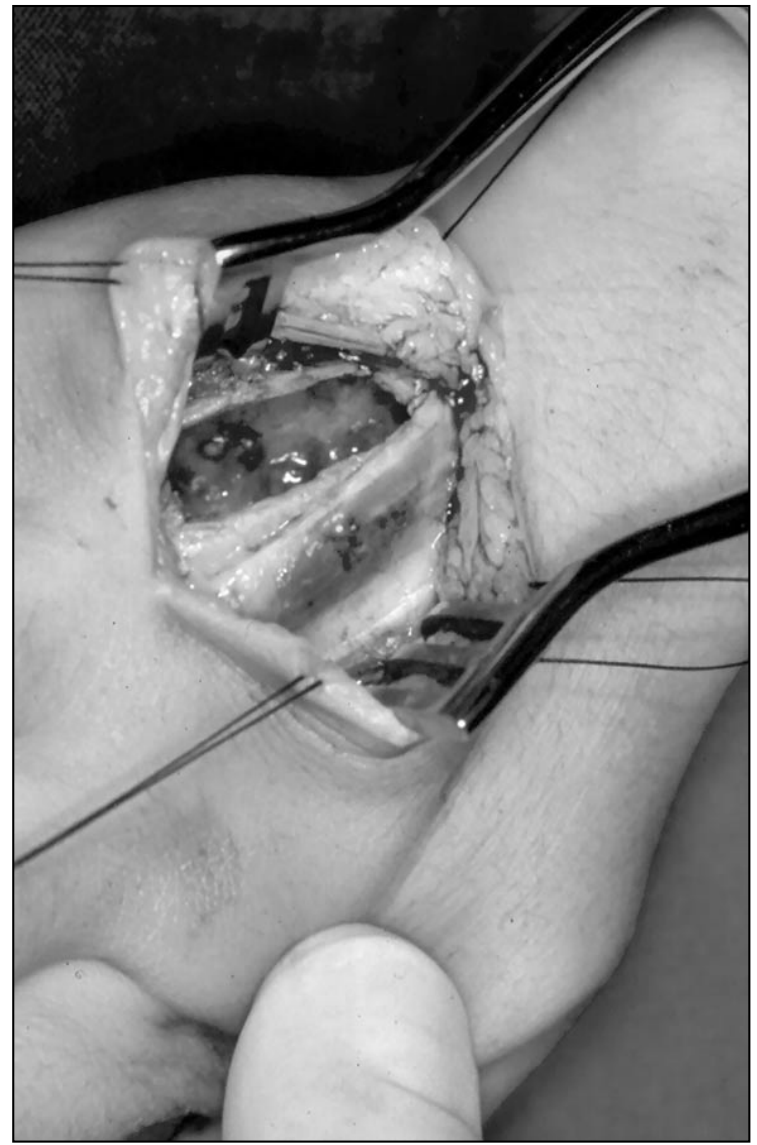

Figura 2. Radiología simple: Lesión insuflante que afecta toda la diáfisis del $4^{\circ}$ metacarpiano.

déficit neurovascular y mantenía un balance articular metacarpofalángico e interfalángico completo.

El estudio radiológico mostró una lesión radiolúcida en la diáfisis del cuarto metacarpiano, de patrón geográfico multilocular, expansiva, simétrica y que adelgazaba las corticales sin interrupción de las mismas. La lesión afectaba toda la longitud de la diáfisis alcanzando el cartílago de crecimiento pero sin mostrar signos de destrucción. El diámetro de la diáfisis en su porción media se hallaba aumentando cuatro veces con respecto al metacarpiano contralateral. Las imágenes no evidenciaban ni reacción perióstica ni de las partes blandas (Figura 2).

Se estableció el diagnostico radiológico de QOA estadio II de Ennekin y se propuso tratamiento quirúrgico: resección-biopsia.

A través de un abordaje dorsal se procedió a la resección intralesional ("curettage") tras exteriorización completa de la lesión por vía de 


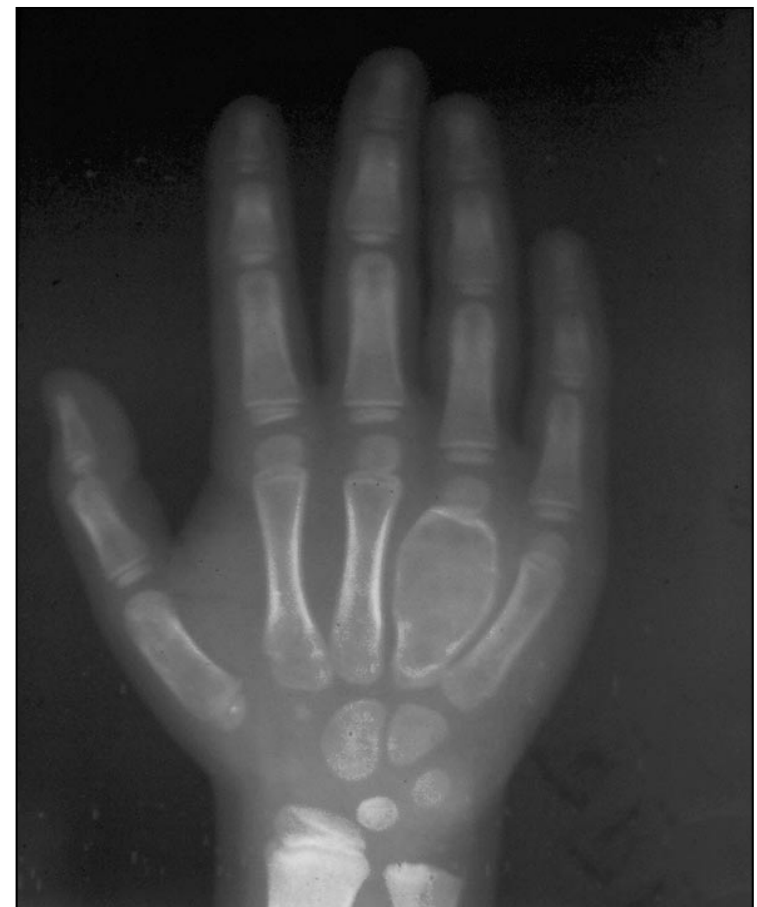

Figura 3. Aspecto intraoperatorio: Exposición completa del quiste previo aporte de autoinjerto óseo.

abordaje dorsal y relleno de injerto óseo antólogo obtenido de cresta ilíaca (Figura 3). El estudio de anatomía patológica confirmó el diagnóstico de QOA.

La evolución fue favorable, con integración precoz del injerto y sin recidiva de la lesión a los 9 años de seguimiento. Se produjo una remodelación y retubulización ósea completa hasta alcanzar el aspecto de hueso cortical tubular con diámetro normal y sin alteraciones del cartílago de crecimiento (Figura 4).

\section{DISCUSIÓN}

El QOA es una lesión benigna, expansiva y osteolítica de etiología incierta. En el niño, a diferencia del adulto, el QOA no suele originarse en lesiones óseas preexistentes. Histológicamente se caracteriza por lagunas de sangre con septos de tejido conectivo.

El QOA aparece a menudo en pacientes jóvenes con cartílago de crecimiento abierto (Burkhalter et al., 1978), siendo la mano una localización poco frecuente (Borrelli et al., 1994).

La edad inferior a 5 años y los patrones radiológicos activos o agresivos (estadio II o III de Ennekin) en el niño menor de 10 años se relacionan con un mayor índice de recidiva (Ramírez et al., 2002, Freiberg et al., 1994).

La complicación más importante de la cirugía del QOA en el niño es la lesión del cartílago de crecimiento, que puede alcanzar el 7,5\% (Ramírez et al.). En nuestro caso, a pesar de que el paciente tenía 5 años de edad, un patrón radiológico activo y la lesión alcanzaba aparentemente el cartílago de crecimiento, el tumor no ha recidivado ni ha afectado la fisis.

El QOA provoca deformación ósea con ensanchamiento y adelgazamiento de la diáfisis.

No se han descrito casos de QOA en la mano en los que se haya obtenido una retubulización completa diafisaria después del tratamiento quirúrgico, incluso tras un seguimiento largo. La resección de la lesión y eliminación de su efecto lesivo, la recuperación de las solicitacio-

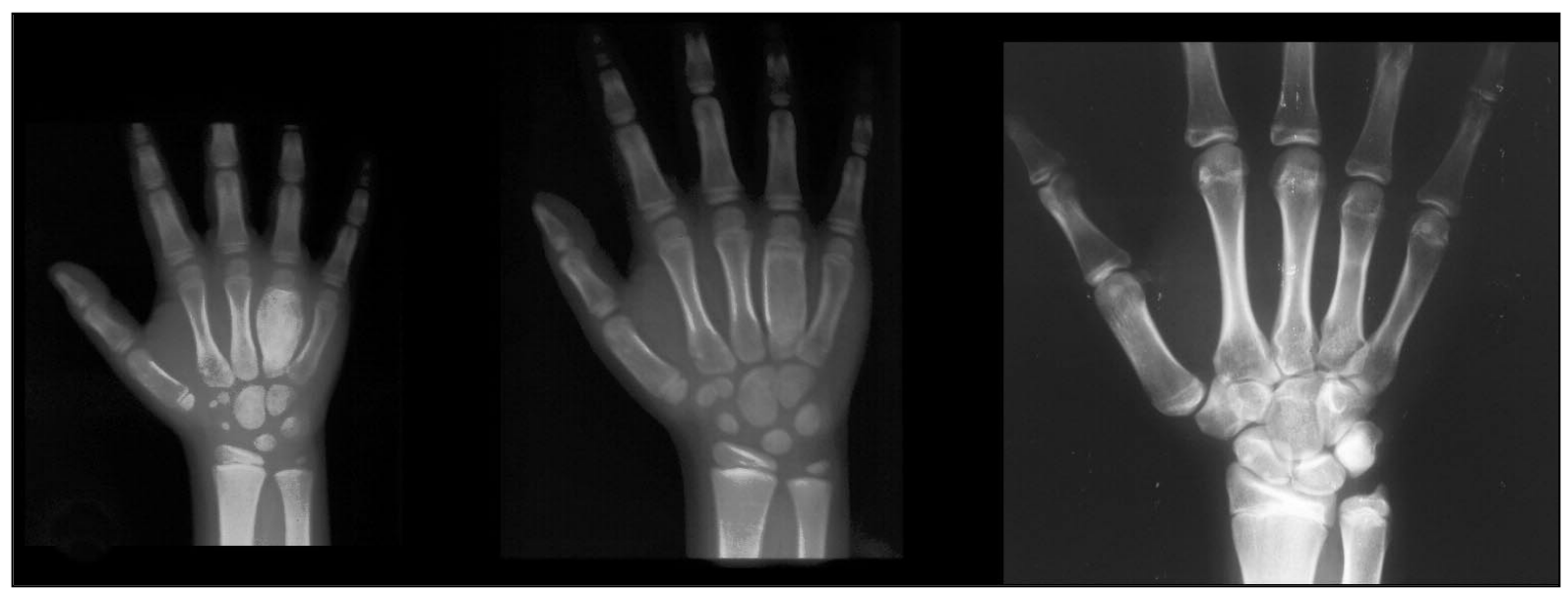

Figura 4. Aspecto radiológico postoperatorio inmediato, a los 14 meses y 9 años. Tubulización diafisaria progresiva y completa. 
nes mecánicas normales (ley de Wolf) y el potencial de crecimiento del paciente han permitido que el proceso de remodelación haya finalizado obteniendo una morfología normal del metacarpiano.

Actualmente se proponen 3 opciones de tratamiento: (1) Resección intralesional (curetage), (2) Resección intralesional más criocirugía y (3) Resección ampliada asociada a aporte de injerto óseo (Athanasian, 1998).

La resección intralesional asocia un alto porcentaje de recidivas (30-60\%) tanto en la mano (Frassica et al., 1998) como en otras localizaciones (Marcove, 1995). Habitualmente las recidivas se relacionan con un curetage incompleto (Frassica et al., 1998).

La asociación de crioterapia y "curetage" aumenta el índice de control local del tumor, con una reducción del porcentaje de recidivas del 49 al 14\% (Marcove, 1995). Athanasian
(1998) considera este método el de elección en el tratamiento de los QOA localizados en la mano.

La resección amplia es una técnica más agresiva pero con gran capacidad de control local de la lesión. No se han descrito casos de recidiva en la mano con este tratamiento de forma primaria o como técnica de rescate de recidivas (Borrelli et al., 1994; Burkhalter et al., 1978; Frassica et al., 1998).

En conclusión, cuando el QOA aparece en pacientes esqueléticamente inmaduros y deforma el hueso, la capacidad de remodelación ósea permite alcanzar de nuevo la morfología original con una retubulización diafisaria completa. La resección intralesional y relleno con autoinjerto del QOA es una opción adecuada de tratamiento si se utiliza una técnica correcta con exteriorización completa de la lesión y puede realizarse sin lesionar el cartílago de crecimiento.

\section{BIBLIOGRAFÍA}

Athanasian, E. A.: Bone and sofá tissue tumors. En: Green, M. D.; Operative hand surgery. $4^{\mathrm{a}}$ Ed. Churchill Livigstone, 1998: 2223-2253.

Borrelli, J.; McCormack, R. R.: Aneurysmal bone cyst involving the long finger metacarpal in a child: A case report. J Hand Surg, 1994; 19A: 800802.

Burkhalter, W. E.; Schroeder, F. C.;
Eversmann, W. W.: Aneurysmal bone cysts occurring in the metacarpals: A case report of three cases. J Hand Surg, 1978; 3(6): 579-584.

Frassica, F. J.; Amadio, P. C.; Wold, L. E. et al.: Aneurysmal bone cyst: clinicopathologic features and treatment of ten cases involving the hand. J Hand Surg 1988; 13A(5): 676-683.

Freiberg, A. A.; Loder, R. T.; Hei- delberg, K. P. et al.: Aneurysmal bone cyst in young children. J Pediatr Orthop. 1994; 14(1): 86-91.

Marcove, R. C.; Dhiren, S. S.; Takemoto, S. et al.: The treatment of Aneurysmal bone cyst, Clin Orthop 1995; 311: 157-163.

Ramírez A. R.; Stanton R. P.: Aneurysmal bone cyst in 29 children. J Pediatr Orthop. 2002; 22: 533-539. 